\title{
Pseudoexfoliation material on posterior chamber intraocular lenses
}

\author{
This article was published in the following Dove Press journal: \\ Clinical Ophthalmology \\ II August 2014 \\ Number of times this article has been viewed
}

\author{
Ricardo António da Rocha- \\ Bastos 1 \\ Sérgio Estrela Silva' \\ Flávio Prézial \\ Fernando Falcão-Reis ${ }^{1,2}$ \\ António B Melo' \\ 'Department of Ophthalmology, \\ Hospital São João, Alameda Prof \\ Hernâni Monteiro, Porto, Portugal; \\ ${ }^{2}$ Department of Sense Organs, Faculty \\ of Medicine, University of Porto, \\ Alameda Prof Hernâni Monteiro, \\ Porto, Portugal
}

\begin{abstract}
The presence of pseudoexfoliation material on the surface of an intraocular lens (IOL) is a rare finding. We report a series of seven cases with different patterns of pseudoexfoliation material deposition on the posterior chamber IOLs, recognized 2-20 years after cataract surgery. Six patients had an IOL implanted in the capsular bag and one in the ciliary sulcus. Two patients had undergone posterior capsulotomy. Although the pathophysiological mechanisms and clinical significance of this finding remain unknown, the careful follow-up of pseudophakic patients with known or suspected pseudoexfoliation syndrome is essential to monitor the development or progression of glaucoma, since deposition of pseudoexfoliation material continues even after cataract surgery.
\end{abstract}

Keywords: intraocular lens, glaucoma, exfoliation syndrome, cataract

\section{Introduction}

Pseudoexfoliation syndrome (XFS) is an extracellular matrix-related disorder that is characterized by the deposition of fibrillar material in virtually all anterior segment tissues and is associated with numerous ocular manifestations, such as ocular hypertension (OHT), glaucoma, zonule weakness, cataract formation, and corneal dysfunction. ${ }^{1}$ Despite some discrepancy between electron-microscopic evidence and histochemical studies, pseudoexfoliation material (XFM) seems to be produced by preequatorial lens epithelium, corneal endothelium, iris, vascular endothelial cells, ciliary epithelium, and trabecular endothelium. ${ }^{1,2}$ Deposition of XFM on the surface of a posterior chamber intraocular lens (IOL) is a rare finding, with few reports published in the literature..$^{3-8}$ The exact pathophysiological mechanisms and clinical significance of this finding are still unknown.

This report describes seven patients with different patterns of XFM deposition on posterior chamber IOLs (Table 1).

\section{Case I}

A 78-year-old woman presented for a routine ophthalmological consultation reporting an uncomplicated bilateral cataract surgery in a private clinic 3 years before. A hydrophobic acrylic IOL (AcrySof ${ }^{\circledR}$; Alcon Laboratories, Inc., Fort Worth, TX, USA) was implanted in the capsular bag bilaterally. There was no known history of glaucoma or OHT. Best-corrected visual acuity (BCVA) was 8/10 oculi uterque (OU) and intraocular pressure (IOP) was $18 \mathrm{mmHg}$ in both eyes. Anterior segment biomicroscopy revealed XFM in the pupillary border and on the anterior surface of the IOL in the right eye (Figure 1A). Posterior segment examination was unremarkable.
Correspondence: Ricardo António da Rocha-Bastos

Department of Ophthalmology, Hospital São João, Alameda Prof Hernâni Monteiro, 4200-3I 9 Porto, Portugal

Tel +35I 917475010

Email rarbastos@gmail.com 
Table I Summary of reported cases

\begin{tabular}{|c|c|c|c|c|c|c|c|}
\hline & & $\begin{array}{l}\text { Cataract } \\
\text { surgery }\end{array}$ & $\begin{array}{l}\text { Time after cataract } \\
\text { surgery }(y r)\end{array}$ & $\begin{array}{l}\text { IOL } \\
\text { location }\end{array}$ & IOL type & $\begin{array}{l}\text { Posterior } \\
\text { capsulotomy }\end{array}$ & Glaucoma \\
\hline \multirow[t]{2}{*}{ Case I } & Affected eye OD & PE & 3 & Bag & Hydrophobic acrylic & - & - \\
\hline & Opposite eye OS & PE & 3 & Bag & Hydrophobic acrylic & - & - \\
\hline \multirow[t]{2}{*}{ Case 2} & Affected eye OS & PE & 2 & Bag & Hydrophilic acrylic & - & - \\
\hline & Opposite eye OD & PE & 2 & Bag & Hydrophilic acrylic & - & - \\
\hline \multirow[t]{2}{*}{ Case 3} & Affected eye OS & PE & 4 & Bag & Hydrophilic acrylic & - & + \\
\hline & Opposite eye OD & PE & 4 & Bag & Hydrophilic acrylic & - & + \\
\hline \multirow[t]{2}{*}{ Case 4} & Affected eye OS & PE & 5 & Bag & Hydrophobic acrylic & - & - \\
\hline & Opposite eye OD & $\mathrm{PE}$ & 5 & Bag & Hydrophobic acrylic & - & - \\
\hline \multirow[t]{2}{*}{ Case 5} & Affected eye OS & ECCE & 19 & Bag & PMMA & - & - \\
\hline & Opposite eye OD & ECCE & 19 & $A C$ & PMMA & - & - \\
\hline \multirow[t]{2}{*}{ Case 6} & Affected eye OD & $\mathrm{PE}$ & 9 & Bag & Hydrophobic acrylic & + & - \\
\hline & Opposite eye OS & $\mathrm{PE}$ & 1 & Bag & Hydrophobic acrylic & - & - \\
\hline \multirow[t]{2}{*}{ Case 7} & Affected eye OS & ECCE & 20 & Sulcus & PMMA & + & + \\
\hline & Opposite eye OD & $\mathrm{ECCE}$ & 20 & Sulcus & PMMA & + & + \\
\hline
\end{tabular}

Abbreviations: AC, anterior chamber; ECCE, extracapsular cataract extraction; IOL, intraocular lens; OD, oculus dexter; OS, oculus sinister; PE, phacoemulsification; PMMA, polymethylmethacrylate; yr, years; +, present; -, absent.

\section{Case 2}

A 68-year-old man was evaluated in a routine ophthalmological examination. He had been submitted to uncomplicated bilateral cataract surgery 2 years before, with implantation of a hydrophilic acrylic IOL (Akreos ${ }^{\circledR}$ Adapt; Bausch \& Lomb Incorporated, Bridgewater, NJ, USA) in the capsular bag. There was no history of glaucoma or OHT, and the patient had no eye complaints. His BCVA was 10/10 OU and IOP was $16 \mathrm{mmHg}$ in both eyes. Slit lamp examination of the left eye showed XFM in the pupillary border and on the anterior surface of the IOL (Figure 1B). Fundoscopy was unremarkable.

\section{Case 3}

A 75-year-old man diagnosed with advanced pseudoexfoliative glaucoma presented for a routine follow-up consultation. He reported bilateral cataract surgery 4 years before, with implantation of a hydrophilic acrylic IOL (Akreos ${ }^{\circledR}$ Adapt; Bausch \& Lomb) in the capsular bag. Also, 1 year later, he was submitted to pars plana vitrectomy in the oculus dexter (OD) due to a rhegmatogenous retinal detachment. His BCVA was light perception OD and hand movement oculus sinister (OS). Anterior segment examination revealed bilateral pupillary margin atrophy and XFM deposition on the anterior surface of the IOL in the left eye (Figure 1C). At that time, IOP was $14 \mathrm{mmHg}$ OD (with brimonidine) and $20 \mathrm{mmHg}$ OS (with travoprost, brimonidine, and a fixed combination of timolol and dorzolamide). The cup to disc (C/D) ratio was 0.9 in both eyes, and the optic discs were pale.

\section{Case 4}

An 80-year-old woman was evaluated in a routine ophthalmological consultation. Bilateral cataract surgery had been performed 5 years earlier, and a hydrophobic acrylic IOL was implanted in the capsular bag (AcrySof ${ }^{\circledR}$; Alcon Laboratories). The BCVA was 10/10 OU and slit lamp biomicroscopy revealed XFM on the IOL surface in the left eye (Figure 1D). The IOP was $12 \mathrm{mmHg}$ OU, and ocular fundus was normal.

\section{Case 5}

An 83-year-old man with known XFS presented for a routine consultation. He reported bilateral extracapsular cataract extraction surgery 19 years before, with implantation of an anterior chamber polymethylmethacrylate (PMMA) IOL in OD and posterior chamber PMMA IOL in the capsular bag OS. Left eye slit lamp examination revealed the presence of XFM on the anterior surface of the IOL (Figure 1E). The patient was being treated with a fixed combination of timolol and dorzolamide OU and IOP was $14 \mathrm{mmHg}$ OU. Fundus examination revealed a $\mathrm{C} / \mathrm{D}$ ratio of $0.5 \mathrm{OU}$.

\section{Case 6}

A 65-year-old woman was referred to the glaucoma department due to OHT associated with XFS. She had previously undergone bilateral cataract surgery ( 9 years before in the right eye and 1 year before in the left), with implantation of a hydrophobic acrylic IOL in the capsular bag (AcrySof ${ }^{\circledR}$; Alcon Laboratories). A neodymium-doped yttrium aluminum garnet (Nd:YAG) laser posterior capsulotomy was performed in her right eye 1 year after the cataract extraction. Her BCVA was 10/10 OU, and IOP was $12 \mathrm{mmHg}$ OD and $18 \mathrm{mmHg}$ OS (with travoprost OU). Slit lamp examination revealed XFM on the posterior surface of the IOL in OD (Figure 2A). Fundoscopy did not reveal any signs of glaucomatous neuropathy. 

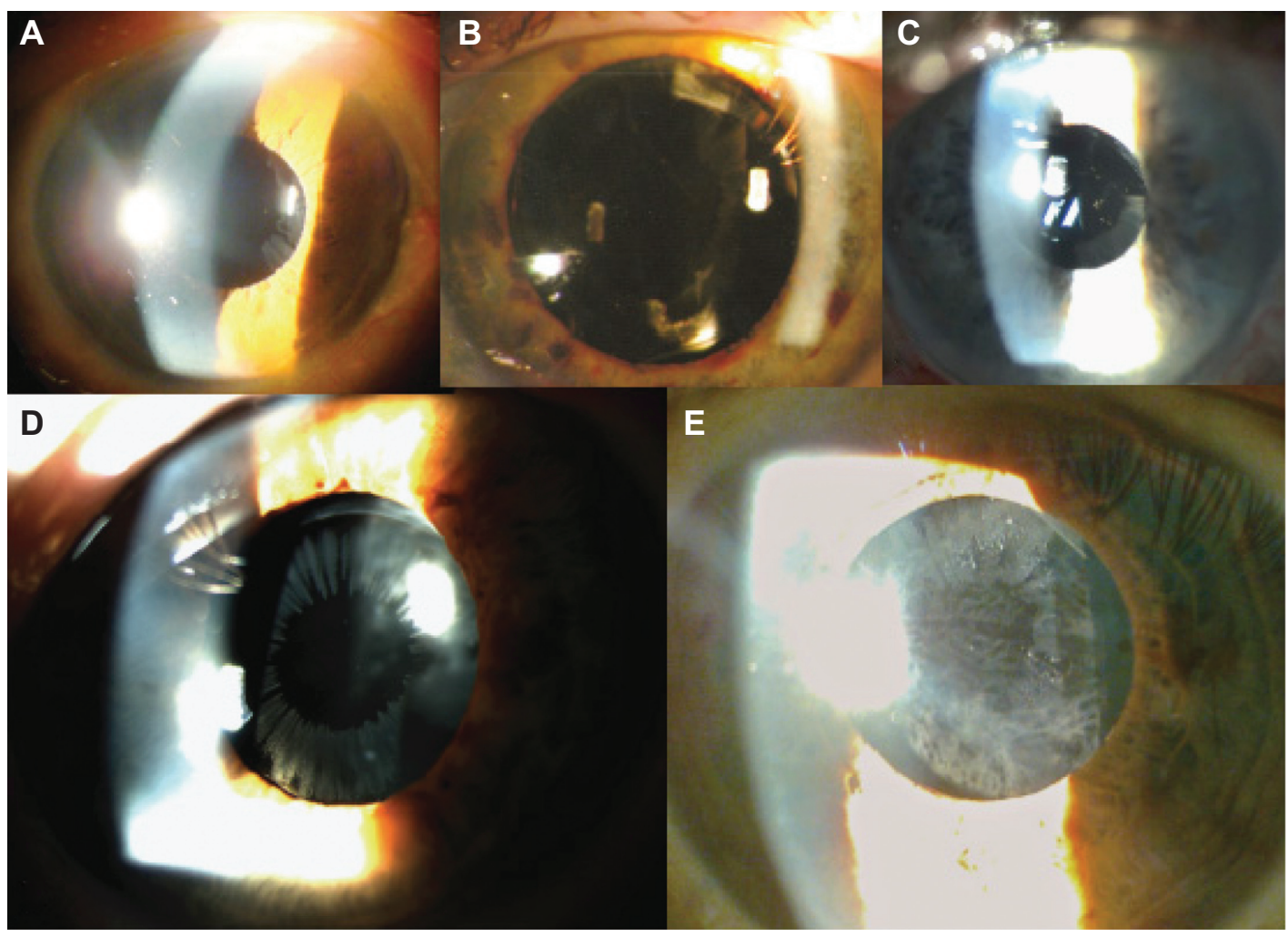

Figure I Deposition of XFM on the anterior surface of posterior chamber intraocular lenses.

Notes: The radiate disposition resembles the typical configuration seen in phakic eyes. (A), case I; (B), case 2; (C), case 3; (D), case 4; and (E), case 5. Abbreviation: XFM, pseudoexfoliation material.

\section{Case 7}

A 91-year-old woman with bilateral advanced pseudoexfoliative glaucoma presented for her follow-up consultation. She had been submitted to a bilateral extracapsular cataract extraction surgery 20 years before, with ciliary sulcus PMMA IOL implantation. A Nd:YAG laser posterior capsulotomy was performed in both eyes 9 years later. Her BCVA was $5 / 10$ OD and 1/10 OS. Slit lamp examination revealed XFM on the posterior surface of the IOL in the left eye (Figure 2B). The IOP was $16 \mathrm{mmHg}$ OU under latanoprost, brimonidine, and a fixed combination of timolol and dorzolamide OU. The $\mathrm{C} / \mathrm{D}$ ratio was 0.9 bilaterally.
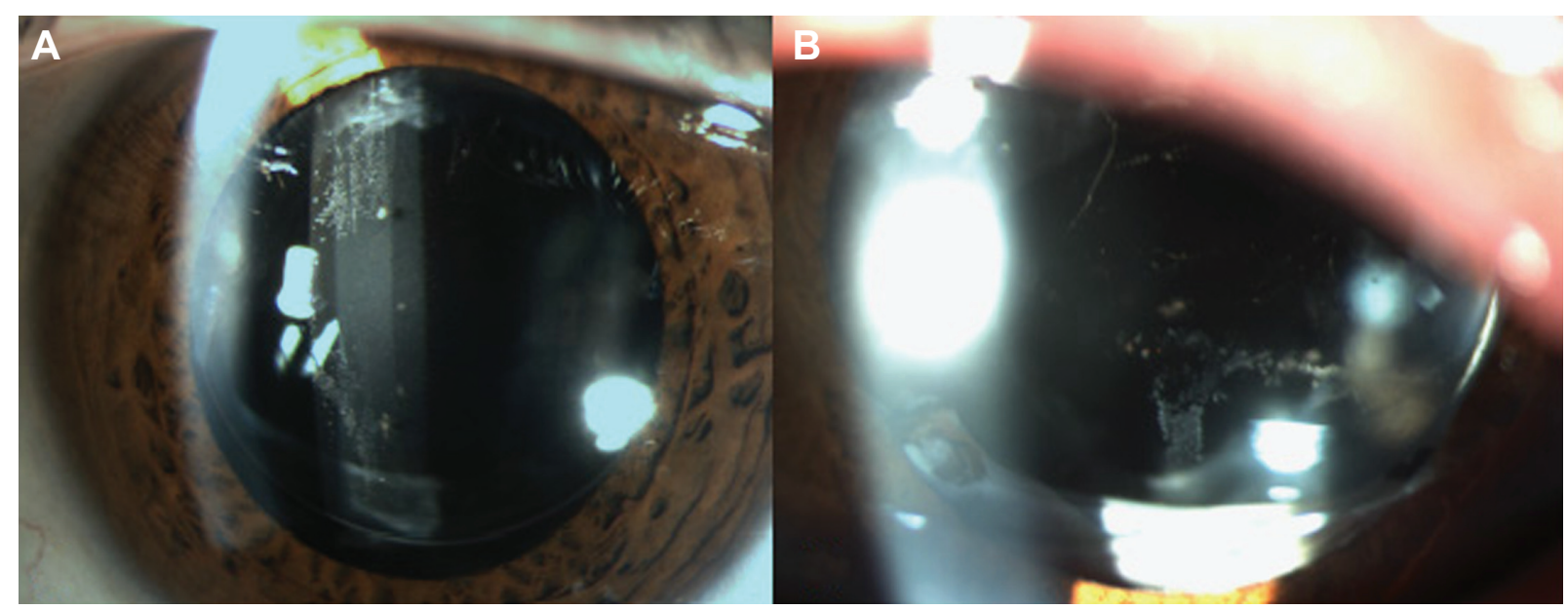

Figure 2 Deposition of XFM on the posterior surface of intraocular lenses.

Notes: These patients were previously submitted to posterior capsulotomy. The vertical pattern of deposition of XFM is distinct from that seen in patients I-5. (A), case 6; (B), case 7.

Abbreviation: XFM, pseudoexfoliation material. 


\section{Discussion}

It is generally accepted that the presence of XFM on the surface of a posterior chamber IOL is a rare finding. Bahadur et al described one case of XFM deposition on a posterior chamber IOL, which appeared to be timely related to a Nd:YAG laser posterior capsulotomy. ${ }^{6}$ Roberts et al also reported this association, and it was proposed that the capsulotomy induced changes in aqueous flow in the posterior chamber that could stimulate XFM deposition on the IOL surface. ${ }^{5}$ However, Park et al published a series of four similar cases of which only one had had a posterior capsulotomy. ${ }^{3}$ In this article, the authors brought to attention the possibility of increased XFM production in tissues adjacent to the IOL, stimulated either by the presence of the IOL in the ciliary sulcus (three cases) or by a scleral buckle inducing ischemia of the ciliary body (one case). The presence of an IOL placed in the sulcus could also be of major importance, given the reduced distance between the IOL and the iris in these particular cases, enabling the deposition of XFM. ${ }^{3,8}$ Later in 2012, Park et al described five patients diagnosed with primary open angle glaucoma, who ultimately presented XFM on the surface of IOL years after cataract surgery. ${ }^{4}$ All patients in this series had an IOL implanted in the capsular bag, contrasting with previous studies.

In our series, we found XFM deposits on the surface of posterior chamber IOLs in seven patients, 2-20 years after cataract surgery, which is - to the best of our knowledge - the largest series of such patients published to date. The IOL was implanted in the ciliary sulcus in one patient (patient 7) and in the capsular bag in six patients (patients 1-6).

The pattern of XFM deposition in cases 1-5 was similar to the classical radiate deposition seen in phakic patients with XFS. In patients 6 and 7, the only patients that had been previously submitted to a posterior capsulotomy, XFM deposits were found on the posterior surface of the IOL. Patient 7 presented a vertical alignment of XFM that could resemble the convection currents of aqueous humor. In patient 6 , this vertical alignment was also present, although not as centered as in case 7. Pseudoexfoliation material also looked more granular when compared to the one found in patients without a previous posterior capsulotomy. We can thus speculate that although a posterior capsulotomy may not be necessary for the presence of XFM in the surface of an IOL, it may influence its pattern of deposition.

In the present report, we describe the presence of XFM on an IOL surface both in patients with (cases 3 and 7) and without (cases 1, 2, 4, 5, and 6) glaucoma. The association between this sign and the presence or stage of glaucoma has not been established so far. ${ }^{3,6}$ Nonetheless, in some previous studies, this finding seemed to be associated with difficult IOP control, new glaucoma diagnosis or faster glaucoma progression. ${ }^{3,4}$

We are still incapable of fully understanding the clinical significance of XFM deposition on the surface of an IOL. Nevertheless, this sign should alert ophthalmologists to the possibility both of progression from XFS to pseudoexfoliative glaucoma and of an increased risk of progression of an already established glaucoma. Due to its subtlety, however, it may go unnoticed for a long time, depriving the patient of a more careful follow-up.

\section{Disclosure}

The authors report no conflicts of interest in this work.

\section{References}

1. Sein J, Galor A, Sheth A, Kruh J, Pasquale LR, Karp CL. Exfoliation syndrome: new genetic and pathophysiologic insights. Curr Opin Ophthalmol. 2013;24(2):167-174.

2. Hietanen J. Origin of exfoliation material. In: Holló G, Konstas AGP, editors. Exfoliation Syndrome and Exfoliative Glaucoma. Savona, Italy: Dogma; 2008:57-66.

3. Park KA, Kee C. Pseudoexfoliative material on the IOL surface and development of glaucoma after cataract surgery in patients with pseudoexfoliation syndrome. J Cataract Refract Surg. 2007;33(10):1815-1818.

4. Park HY, Ahn MD. Cases of pseudophakic pseudoexfoliation in glaucoma patients. Korean J Ophthalmol. 2012;26(5):402-405.

5. Roberts MA, Hawksworth NR. Pseudophakic pseudoexfoliation of an AkreosFit intraocular lens. Eur J Ophthalmol. 2009;19(6): 1082-1083.

6. Bahadur GG, Masket S. Pseudophakia with pseudo-pseudoexfoliation. J Cataract Refract Surg. 2007;33(10):1827-1828.

7. Kumaran N, Girgis R. Pseudoexfoliative deposits on an intraocular lens implant. Eye (Lond). 2011;25(10):1378-1379.

8. Hepsen I, Sbeity Z, Liebmann J, Ritch R. Phakic pattern of exfoliation material on a posterior chamber intraocular lens. Acta Ophthalmol. 2009; 87(1):106-107.
Clinical Ophthalmology

\section{Publish your work in this journal}

Clinical Ophthalmology is an international, peer-reviewed journal covering all subspecialties within ophthalmology. Key topics include: Optometry; Visual science; Pharmacology and drug therapy in eye diseases; Basic Sciences; Primary and Secondary eye care; Patient Safety and Quality of Care Improvements. This journal is indexed on Submit your manuscript here: http://www.dovepress.com/clinical-ophthalmology-journal

\section{Dovepress}

PubMed Central and CAS, and is the official journal of The Society of Clinical Ophthalmology (SCO). The manuscript management system is completely online and includes a very quick and fair peer-review system, which is all easy to use. Visit http://www.dovepress.com/ testimonials.php to read real quotes from published authors. 